\title{
IUTAM Symposium on Hamiltonian Dynamics, Vortex Structures, Turbulence Москва, 25-30 августа, 2006
}

С 25 по 30 августа 2006 г. в Математическом институте им. В. А. Стеклова РАН был проведен IUTAM Symposium on Hamiltonian Dynamics, Vortex Structures, Turbulence - Международный симпозиум «Гамильтонова динамика. Вихревые структуры. Турбулентность» под эгидой Международного союза по теоретической и прикладной механике (IUTAM). Со-организаторами симпозиума выступили Российская академия наук, Математический институт им. В. А. Стеклова и Институт компьютерных исследований. За шесть дней работы симпозиума было сделано 19 пленарных (40 мин) и 47 секционных (20 мин) докладов. Кроме этого, была проведена мемориальная секция, посвященная памяти профессора В. И. Юдовича, и был выслушан доклад M. Питерса (M. Peters), представителя издательства Springer-Verlag, Heidelberg. В работе симпозиума приняли участие ученые из 11 стран - Бразилии, Франции, Израиля, Италии, Японии, Литвы, Нидерландов, России, Великобритании, Украины, США.

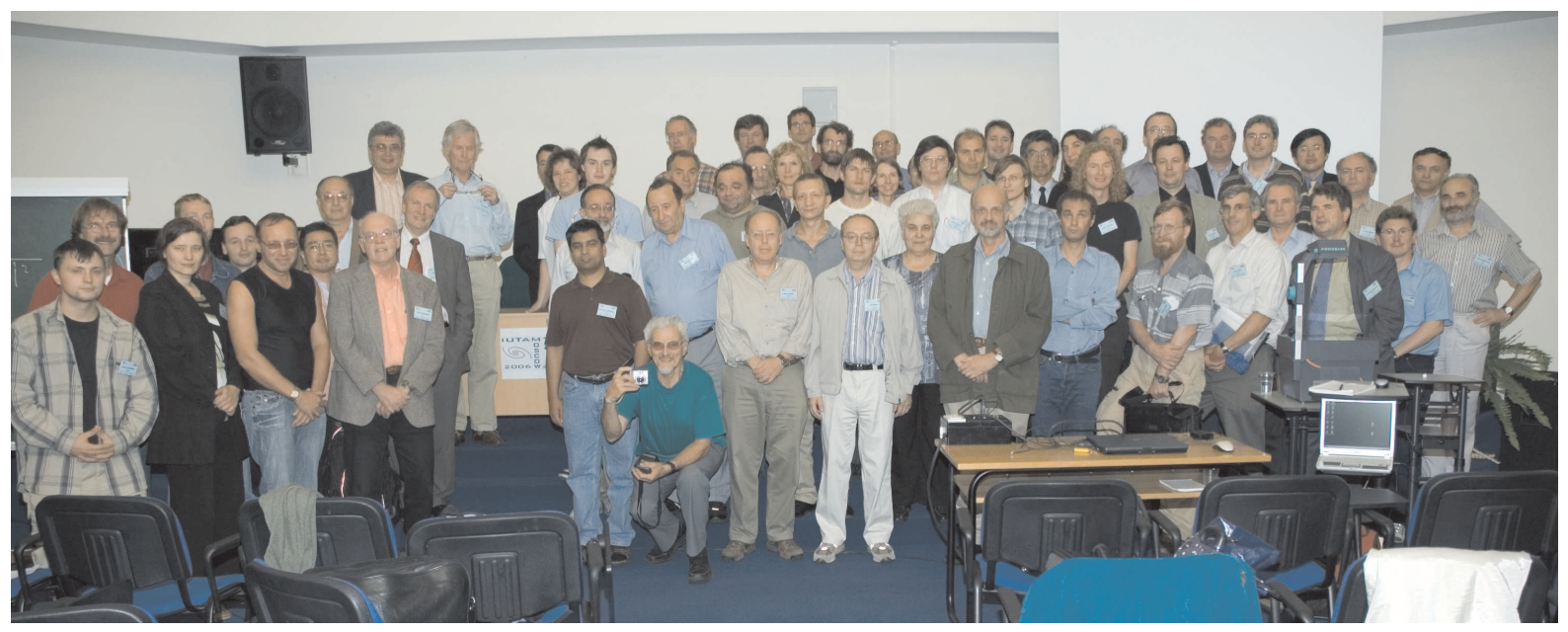

Коллективное фото участников симпозиума ${ }^{1}$

В последние десятилетия научное сообщество осознало тот факт, что прогресс при исследовании турбулентных вихревых движений в реальных средах возможен только на основе комплексного использования строгих математических методов, компьютерных исследований, лабораторного и натурного моделирования. В каждом из перечисленных подходов получены интересные результаты, которые позволяют изучать процессы с новых позиций. Данный симпозиум был организован в целях объединения опыта специалистов разных направлений, работающих над проблемами гамильтоновой динамики, теории вихревых структур и турбулентности. Доклады участников были посвящены обсуждению известных результатов, а также новых проблем и концепций, имеющих отношение к указанным темам. Были рассмотрены как фундаментальные, так и прикладные аспекты процессов формирования и эволюции различных течений, волн, когерентных структур в жидкости и газе. Большое внимание было уделено исследованиям нелинейных регулярных и хаотических режимов вихревых взаимодействий, адвективных и конвективных движений.

\footnotetext{
${ }^{1}$ Фотографировала О. Мисюрина.
} 


\section{Научный комитет симпозиума:}

В. В. Козлов (председатель, Россия),

А. В. Борисов (сопредседатель, Россия),

П. А. Девис (сопредседатель, Великобритания),

Ж. Веррон (сопредседатель, Франция),

K. Моффатт (представитель IUTAM, Великобритания),

Х. Ареф (США), В. В. Бердичевский (США), Д. Блэкмор (США), К. Картон (Франция), Р. Гримшоу (Великобритания), Х. ван Хейст (Нидерланды), 3. Кизнер (Израиль), К. В. Кошель (Россия), И. С. Мамаев (Россия), В. В. Мелешко (Украина), Г. Резник (Россия), М. А. Соколовский (научный секретарь, Россия), В. И. Юдович (Россия), Г. М. Заславский (США).

Работа симпозиума проходила в рамках следующих секций:

- Проблемы турбулентности;

- Гамильтонов формализм и его приложения к динамике дискретных структур и сплошных сред;

- Математические методы теории вихрей;

• Лабораторное и натурное изучение турбулентности и вихрей;

- Устойчивость и бифуркации;

- Компьютерные методы исследования динамических систем;

- Теория интегрируемости;

- Проблемы геофизической гидродинамики.

С пленарными докладами на симпозиуме выступили К.Моффатт, Х.Ареф, Ж.Веррон, Я. Фукумото, Х.Я.ван Хейст, Ж.Йоосс, Ш. Кида, Й. Қимура, А. В. Борисов, И. С. Мамаев, 3. Қизнер, В. В. Козлов, В.В.Мелешко, А. Нейштадт,Н.Палдор, Г. Резник, В. Владимиров, С. Виггинс, В. Е. Захаров, Г. Заславский, Ч. Лим.

Полный перечень докладов приведен на сайте симпозиума http://conf2006.rcd.ru/.

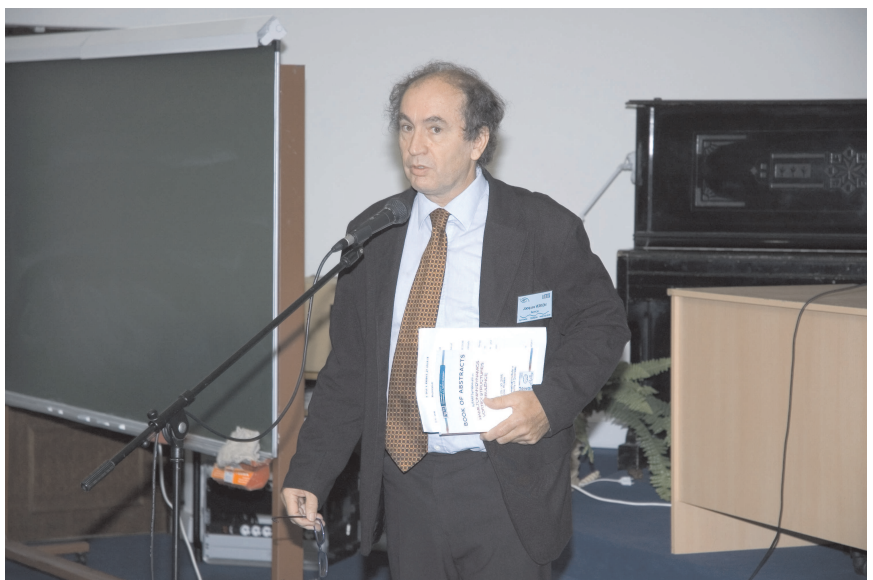

Ж. Веррон. Выступление на открытии симпозиума 


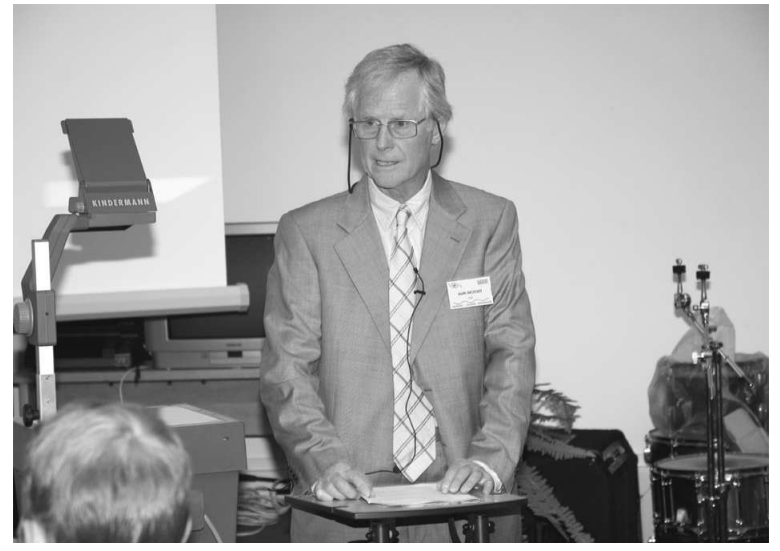

K. Моффат. Вступительное слово на открытии симпозиума

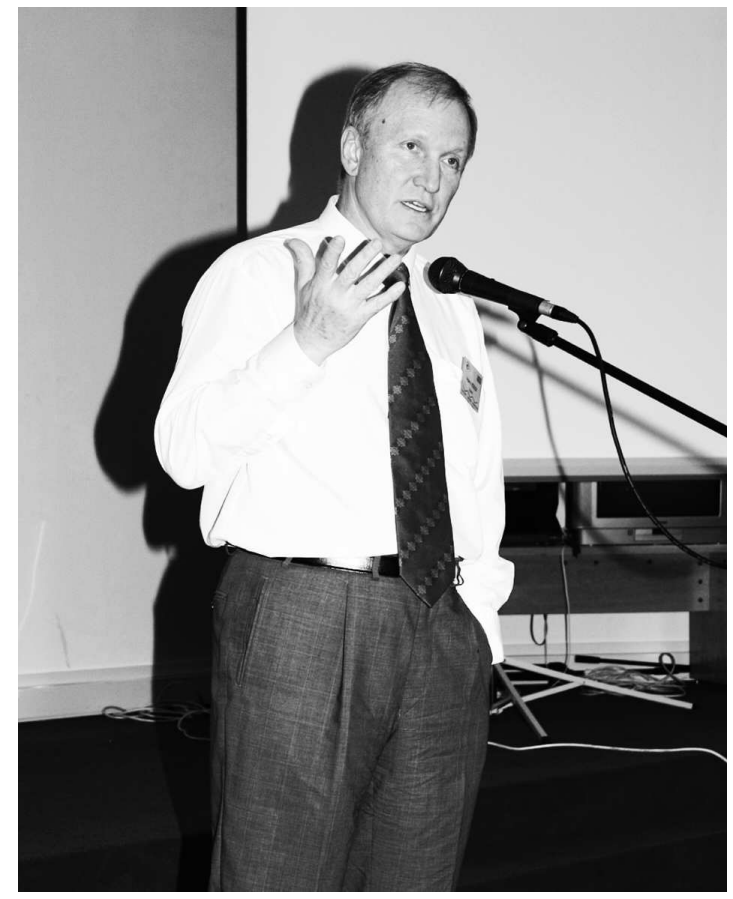

B. В. Козлов. Пленарный доклад $O n$ Lagrangian Turbulence

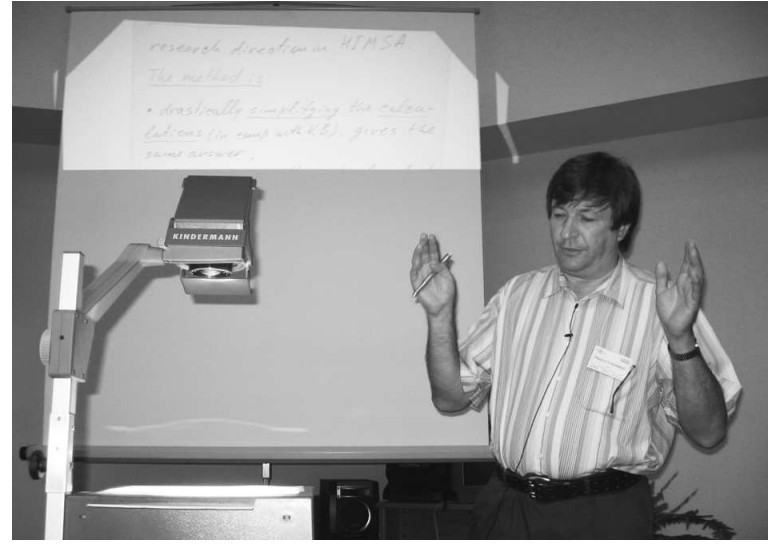

В. Владимиров. Мемориальная секции памяти В. И. Юдовича

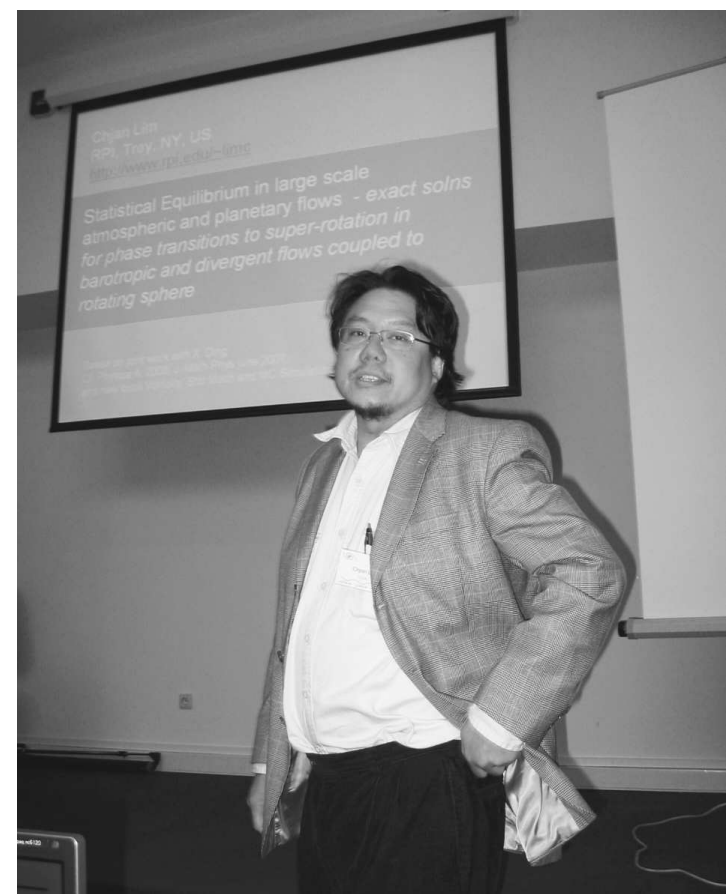

Ч. Лим. Пленарный доклад Stability and phase transition to super-rotation in barotropic vortex dynamics on a rotating sphere

Помимо научной программы многие участники, особенно зарубежные гости, приняли участие в социально-культурных мероприятиях. Большим успехом у участников симпозиума пользовалась организованная в дни конференции выставка-продажа книг Научно-издательского центра «Регулярная и хаотическая динамика». 

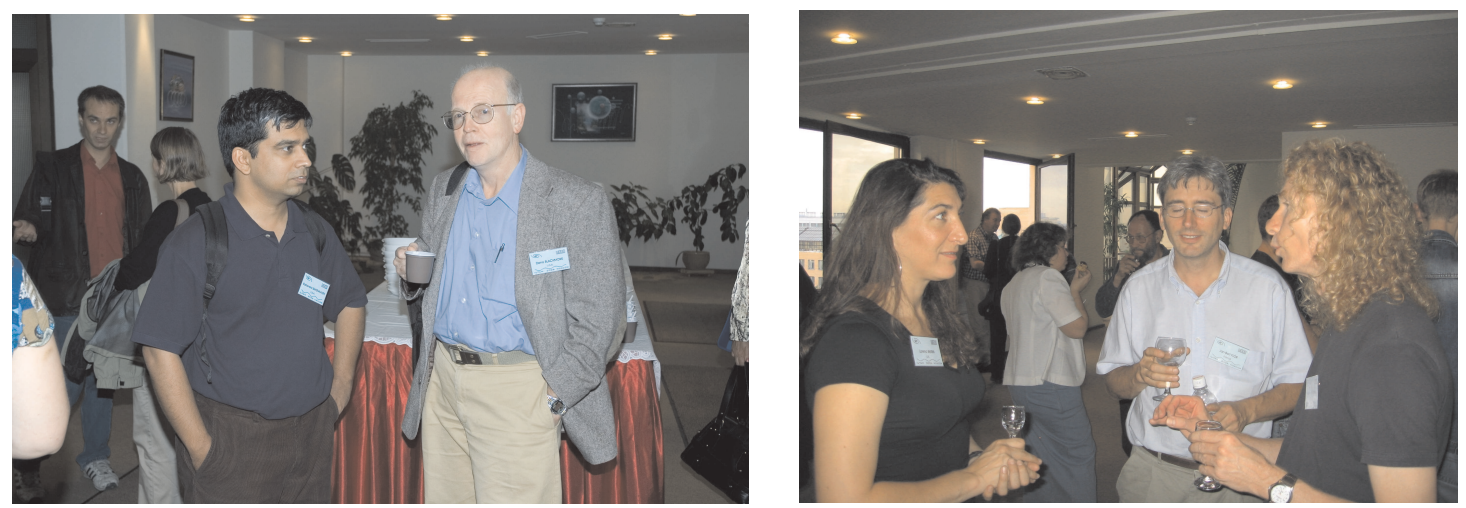

В перерывах между заседаниями
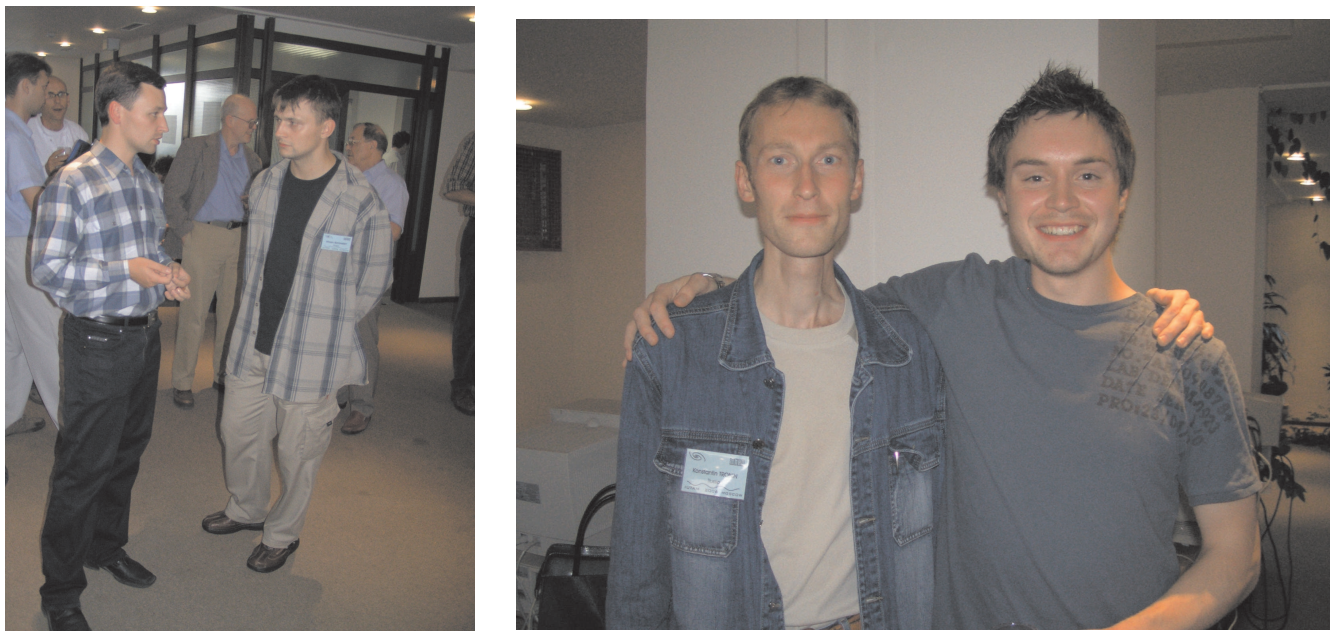

Молодые участники симпозиума

По единодушному мнению участников, IUTAM-симпозиум «Гамильтонова динамика. Вихревые структуры. Турбулентность» был проведен с большим успехом, на высоком научном и организационном уровне.

В этом номере мы приводим несколько работ приглашенных участников симпозиума, представляющих собой русские переводы статей, подготовленных к публикации в Proceedings of the IUTAM Symposium on Hamiltonian Dynamics, Vortex Structures, Turbulence - трудах симпозиума, которые будут опубликованы издательством Springer-Verlag в 2007 году.

Отметим, что в 2008 году в Дании будет проводиться IUTAM Symposium on 150 Years of Vortex Dynamics. Краткая информация об этом симпозиуме размещена на сайте IUTAM (http://www.iutam.net) в разделе Event calendars, IUTAM Symposia. 